\title{
Cross-Cultural Skype Conversation in Improving Students' Speaking Production and Grammar
}

\author{
Suci Tresna Dewi Handayani \\ English Education Study Program \\ Universitas Pendidikan Indonesia \\ Bandung, Indonesia \\ sucitresnadh@upi.edu
}

\begin{abstract}
Generation $\mathrm{Z}$ students with millennial spirit $\mathbf{4 . 0}$ are always expected to increase their competitiveness globally. One of the elements to compete is the ability to speak English with good grammar. A tertiary school in Bandung adopts CrossCultural Skype Conversation (CCSC) to improve students' English-speaking production and grammar. This study aims to analyze how it is implemented and how the students view it. Data were collected through classroom observation to see how CCSC was implemented. To get the students' perceptions, a questionnaire was distributed to $\mathbf{4 2}$ Engineering students, after it was tabulated and analyzed, 2 students with opposite perception were chosen to be interviewed. The result of the observation shows that CCSC is carried out in turn in a way that one student talks to English speakers from other countries, while other students write one's grammar mistakes. While questionnaire and interview analysis show that $74 \%$ of students agree that CCSC can improve their speaking production and grammar as they can talk more, and they tend to be able to understand and reply to what their interlocutors ask. Corrections regarding grammar errors are rarely encountered.
\end{abstract}

Keywords: Cross-Cultural Skype Conversation, grammar, speaking production, synchronous computer-mediated communication

\section{INTRODUCTION}

Generation $\mathrm{Z}$ tends to have a dependency on technology by embracing social learning environments, they are not interested in just showing up in class, attending lectures, and noting that they will memorize for an exam later (College, 2015). Instead, they want to be directly involved in the learning process with low access barriers to support self-actualization. It uses as an effort to get jobs by the demands of the era where major and radical changes to the way humans produce goods and cooperate with foreign colleagues are faced.

Sometimes video conferencing is used as a technique by most teachers to answer these challenges. The educational uses of video conferencing with foreign interlocutors have been examined by many English as a Foreign Language (EFL) researchers as Coverdale-Jones (2017) stated that by using video conferencing application, learners have more opportunities to interact with other language learners and people from different parts of the world who speak the target language. From the statement, it means language learners are exposed to different cultures, language usage, and accents.
Eguchi (2014) reported that cross-cultural video conferencing made EFL learners in Japan felt more comfortable and produce more utterances by conversing in English with Mexican who had better English-speaking skill and were affected by the energy and speaking speed of the Mexican students compared to English speaking practice which was carried out among Japanese learners. From the result of the study, it is required to also investigate how the Japanese students perceived their Japanese peers, and cross-cultural interlocutor was only from Mexico. It is also required to have more than one cross-cultural interlocutor at least who are from several countries in the world who do not have too many time differences. Additionally, Taillefer and Munoz-Luna (2014) reported that EFL students in Hong Kong preferred only to use non-verbal communication when they talked to native English speakers of Spain through Skype-mate Language Project because they did not understand what the Skype friends said.

To improve students' speaking production, several studies also state that conversations conducted with speakers or English learners through synchronous conversations can increase understanding of grammar. Nasr and Mustafa (2018) emphasized that Skype had a great impact on all speaking test including the grammar of 22 beginners EFL from Arab Open University who practiced their spoken English with English speaker from South Africa, United States, and the United Kingdom about the importance of English and Internet, advantages and disadvantages of living in cities and villages, and something they want in the future using cross-cultural synchronous communication.

Research on the use of Skype in improving speaking production and grammar has been conducted in multiple contexts. Starting from the lack of courage of Japanese students in speaking (Taillefer \& Munoz-Luna, 2014), then the finding of another study in Japan proves that this has succeeded in increasing English speaking production (Eguchi, 2014), and enhancing students' grammar understanding (Nasr \& Mustafa, 2018).

One of Tertiary School in Bandung uses Skype as a medium to improve the speaking production and grammar of its students. Students talk through Skype with people from different cultures on some topics such as weather, food, opinions and some other things. Then why does the lecturer use Skype? The English lecturer answered that other social media 
does not support video calls when it is opened into the website version, another reason is that he uses a speaking website that only provides an option for us to fill in the address of social media, one of which is social media that students are familiar with namely Skype.

\section{METHOD}

This study employed a descriptive qualitative approach. Qualitative research was selected as Creswell (2012) and Fraenkel, Wallen, and Hyun (2012) clarified that this enables the researcher to obtain an in-depth analysis of the issue being investigated. Also, qualitative research is a naturalistic approach to explore a phenomenon (Ritchie, 2013), as the researcher wanted to find out how CCSC is implemented to improve students' speaking production and how the students view it.

The research site of this study is at one of the tertiary schools in West Java, Indonesia, involving 42 students from 2 classes of English 2 subjects that use CCSC as a way to improve their speaking production and grammar.

For collecting the data, video-recorded classroom observation was taken two times to obtain the data and information about the actual implementation of CCSC in improving speaking production and grammar.

Other instruments are questionnaires and interviews. The students were given the questionnaire to be filled related to the research question number two about what are their views on its use to improve their speaking production and grammar, after it was tabulated and analyzed, to further reinforce the overall perceptions of the students the researcher took 2 students with opposite perceptions to be interviewed of how they view it more in detail.

In this study, the researcher analyzed the data by using Interactive Model Analysis containing three linked subprocesses, those are; data reduction, data display, and conclusion drawing or verification (Huberman \& Miles, 1994). All the subprocesses are taken during and post or after the data were collected to confirm or to validate the data from observation.

\section{FINDINGS AND DISCUSSION}

\section{A. The implementation of CCSC to improve English speaking production and grammar in the classroom}

When researchers conducted observations, the teacher was implementing the CCSC to improve English speaking and grammar production in the form of a Simple Present Tense. The implementation is in 150 minutes in 1 meeting that is divided into two main activities that begin with reviewing previous material about "what is a sentence?", and followed by explaining the material by the teacher and practicing spoken English about habit and fact by the students with foreign interlocutors through Skype.

\section{1) Giving "Simple Present Tense" Material}

The teacher gives "Simple Present Tense" material by asking first whether students think that the verbs in Indonesian and English sentences are the same or not, then the teacher explains about tenses by explaining the material (aims, and form of simple present tense) through PowerPoint slides, and then gives the example of simple present tense through video downloaded from YouTube, ended by a material discussion where the students ask the teacher or vice versa about the material has been given and received.

\section{2) Practicing Spoken English Related to the Material}

The learning activity then is continued by English speaking practice that is done synchronously using Skype between the students and foreigners from other countries available to make students engage with other interlocutors who have a different cultural background, the teacher hopes it can build students cultural awareness by conversing something related to the foreigners' habits and facts and reinforces the students to express statement and ask questions related to habit and facts.

The teacher believes there will be many statements and questions about habits and facts stated and asked from the students and vice versa, because they do not know each other which force the student to ask something facts related to identities like name, age, and origin, they also have a different cultural background that perhaps have also different habits, so the more they ask and state it, the more they produce utterances.

Skyping between the students and foreigners from other countries who available on Skype started with giving a brief explanation about its rule by the teacher that one student comes forward and puts him/herself as a speaker and the rest of the students become writers (correctors) and wait for their turn, then the speaker sits in front of the teacher's laptop and talks to the foreigner in English orally about habits and facts at least 20 sentences in 5 minutes.

The writers (correctors) watch and listen to the conversation through projector and speakers while waiting for their turn and write any error of what sentences the speaker says while conversing with the foreigners in terms of the use of the verb, kinds of sentences (active and passive verbal) or nominal sentences in the simple present tense rules and give a correction to it.

The teacher gives the speaker score by counting on how many sentences the speakers say and how many error sentences she/he made, and gives the writer score by counting how many right corrections they corrected towards the speakers what sentences the speaker says.

After explaining the rules, the teacher makes sure that all tools such as laptops, projectors, speakers, and Internet connections are ready to be used, and opens a Skype account and contact one of her Skype friends (the foreigner) to talk to her students synchronously.

One student (the speaker) talks to the foreigner in English orally about habits and facts approximately in 5 minutes. When they speak there were accuracy and also errors in using grammar. The excerpts of conversations that occur between speakers and foreigners via Skype are as follows: 
Excerpt 1: Conversations between student and foreigner via Skype using proper grammar.

$$
\begin{aligned}
& \text { S: How old are you? } \\
& \text { F: I am twenty-six }
\end{aligned}
$$

Excerpt 2: Conversations between student and foreigner via Skype with grammar errors.

$\mathrm{S}:$ What is your hobby?

F: My hobies is to travel and hunting birds.

Other students (writers) watch and listen to the conversation through projector and speakers while waiting for their turn and write any error of what sentences the speaker says while conversing with the foreigners in terms of the use of the verb, kinds of sentences (active and passive verbal) or nominal sentences in the simple present tense rules and give a correction to it. Table I. shows the example of giving correction by the writers.

TABLE I. EXAMPLE OF WritTEN CORRECTIVE FEEDBACK GIVEN BY THE CORRECTORS

\begin{tabular}{|l|c|}
\hline \multicolumn{2}{|c|}{ Student A } \\
\hline $\begin{array}{c}\text { Sentences that I think are not } \\
\text { proper }\end{array}$ & The sentence should be like these \\
\hline I has a program & I have a program (verb) \\
\hline Do you afraid of an error? & Are you afraid of an error? (nominal) \\
\hline Are you go to work by train? & Do you go to work by train? (verbal) \\
\hline
\end{tabular}

Meanwhile, the teacher gives corrective feedback orally and sometimes corrective feedback comes from the foreigners (the foreign interlocutor) they (the speakers) talk to.

The second column from Table I. is the writer's corrections towards the speaker's utterances, if the correction is true, the teacher gives a point for the writer, but if it is false the point is not given.

After all the students have all their turns, the teacher leads the students to discuss all error sentences they have spoken and written. To train the students' grammar use, corrective feedback is needed. It is defined as information given to students about the linguistic mistakes, they have made (Loewen \& Erlam, 2006).

It is needed because students make mistakes in learning. Errors in teaching perspective show information about what students still need to learn. Feedback given by other students is a form of motivation for the one who as the speaker and indirectly trains themselves to express a sentence or more by using the correct grammar.

In the practice of giving feedback, the teacher engages other students to improve their abilities in analyzing the wrong words. Written corrective feedback refers to usage in writing that is not by the norms of the target language that can be given by peers. Besides, oral corrective feedback shows corrections to correct the bad forms of linguistic units used to speak.

Corrective feedback was given by the teacher when students use the wrong form of the target language. The teacher uses metalinguistic and explicit correction. Here are the common grammar mistakes made by the students and common corrective feedback given by the teacher.
Excerpt 3: Common grammar mistakes and teacher corrective feedback.

S: What is your hobbies?

T: What are your hobbies? are ya...

$\mathrm{S}$ : Yes, She have many friends

T: Have apa has? Do we say have?

In providing corrective feedback like these, the teacher also intends to be a role model who exemplifies how to provide feedback when the students find errors, this also indirectly contributes to the development of the student's character.

Explicit and metalinguistic feedback given by the teacher when the students make mistakes can stimulate the students' good character, because in metalinguistic feedback, for example, the teacher indirectly justifies the wrong word, she clarifies the wrong word by asking first (Muhsin \& Sastrawati, 2015), by using that way, students can get good examples from their teacher when they want to give feedback to their friends.

Student mistakes are expected to be corrected after they get a correction (Solikhah, 2016). The English teacher in this study also hopes that by using this method, students can correct each other and learn from their mistakes in using verb types that are appropriate to the subject and the type of sentences whether the sentences they use are active or passive.

In addition to providing feedback from teachers and other students, the assessment process or grading is also carried out by the teacher. In the practice of improving English speaking production, the teacher determines how many sentences limits they should say and counts directly how many sentences the speakers say and how many error sentences she/he made. In this activity, teaching time is a limitation for the students' freedom to express something, this becomes an obstacle for teachers to improve their English-speaking production because of the time and number of students who do not allow the students to use more than 5 minutes.

This short duration can cause student discretion in expressing the sentences they want to say because the duration they get to converse with the foreign interlocutors is very limited, which is only 5 minutes.

Internet constraints will also be a reason where students feel uncomfortable in speaking because it can cause unclear sounds or messages delivered by interlocutors will often pause and messages will be delivered by students will also be disrupted, and the possibility of always repeating messages will often occur.

However, students seemed enthusiastic to carry out the learning activity, most of them seemed very happy to be able to talk with foreigners from other countries, sometimes they told jokes even though their grammar mastery was not quite right. CCSC was seen to motivate students to speak both asking and answering questions from foreign interlocutors called foreigners.

This has also been discovered by other researchers who prove that it is interesting. A survey after conducting an English video conference session between participants in Japan 
and Thailand showed that students were motivated to communicate in English and felt their English abilities improved (Shiozawa, 2005), then a language course involving video conferences between Japan and Korea and reported that more than $80 \%$ of students felt their speaking ability improved after video conferencing (Owada, 2005), and in Taiwan found improvement in language skills after video conferencing sessions with Japanese partners (Lin, 2007).

Besides many students who looked enthusiastic, some students looked confused and nervous. As a result, students only answered using body language like nodding. The teacher also motivated them to ask or answer questions that the foreign speaker asked. Other students (correctors) sometimes even played a role as speakers with answering questions asked by foreigners to the speakers.

Research in Hong Kong also reported that EFL students in Hong Kong were preferred only use non-verbal communication when they talked to native English speakers of Spain through Skype-mate Language Project because they did not understand what the Skype friends said (Taillefer \& Munoz-Luna, 2014).

In this case, we can find out that only a few students were nervous, most students were so highly motivated to have online conversations with foreigners, but how can this be questioned in the terms of improving English speaking production and the use of appropriate grammar? This will be discussed in point B of what they feel and perceive about improving their Englishspeaking production and mastering their grammar through online conversations.

\section{B. Students Perceptions towards the Implementation of CCSC in Improving Speaking Production and Grammar}

The Figure 1 is the result of filling out a questionnaire by students to show their level of agreement on a series of questions about the perception of CCSC implementation in improving English speaking production and grammar.

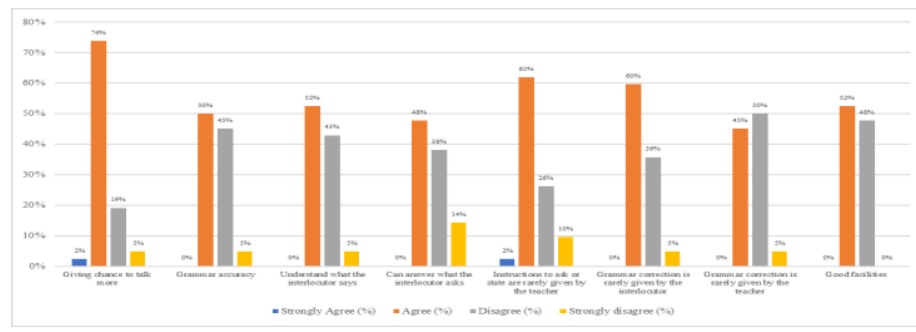

Fig. 1. Students Perceptions towards the Implementation of CCSC in Improving Speaking Production and Grammar

The Figure 1 shows that $74 \%$ of students agree that CCSC gives them the opportunity to say more, $52 \%$ of students choose that they can be able to understand what was said by the foreigners and $48 \%$ students agree that they could answer what the foreigners asked in English and $62 \%$ of the students agree that instructions given by the teacher to speak were rarely given because students actively asked and answered questions.

Transcription of interviews with students who have a positive response states that they have a high enough curiosity, so not only answers but also many questions that are spoken to find out the identity and culture of the foreigners, the statements and questions that are raised are about the identity and habits using simple present tense like "What is your name?", "What do you usually eat in the morning?" or tell their experiences using the simple past tense. She says that CCSC motivates her to speak.

Other studies also state that Skype is effective to be used in learning English speaking, it develops the EFL learners' speaking skills and motivate the EFL learners to improve their speaking skills (Khan, Ayaz, \& Khan, 2016) and Tsukamoto and Senzaki (2009) pointed out that EFL students in Japan clearly enjoyed speaking with American students through the Skype conferences. It significantly increased student motivation to study English. Students have more chances to use real communication of English and their motivation to study becomes higher. They speak more English even though their teachers do not force them because web conferencing is enjoyable to them.

Using Skype conversation with interlocutors from different countries also can add students' knowledge and make them aware about cultural differences as Guth and Marini-Maio (2010) suggested that an intercontinental telecollaboration between Italian who learn English students at the University of Padova, Italy, and American who learn Italian students at Dickinson College, USA. Students use Skype for weekly synchronous conversations. Skype sessions were seen as an opportunity to become more familiar with some American pronunciations as well as American cultures. It also improved students' English communication.

Ip (2012) confirmed that SCMC enhanced the intercultural communication skills of Swedish students, as Piasecka and Tukiendorf (2014) stated that the Internet is a great source of authentic English. EFL learners can be able to practice English speaking and expand their cultural knowledge by getting closer to other cultures.

On the other hand, the student with negative perception says that he does not understand what the foreigner says, and he is nervous that he cannot or rarely speak actively, he becomes passive and only relies on body language when answering, such as nodding. When he nodded, he understood what foreigners asked but he could not reply to what foreigners asked in English. It is also experienced as a finding from Taillefer and Munoz-Luna (2014) study about preference where students choose to use body language when they do not understand what the other person is saying through Skype.

In terms of grammar accuracy, 50\% of students agree that by using CCSC they could speak with correct grammar but $45 \%$ of them stated otherwise, and the Figure 1 shows that only $36 \%$ of students agree that the corrective feedbacks from the foreigners towards their grammar errors were rarely given, but $50 \%$ of students stated that their teacher rarely reminds them for their grammar mistakes.

Grammar mastery is seen not too well. This is contrary to the results of the study Nasr and Mustafa (2018) emphasize that Skype conversation with foreign interlocutors had a great impact on grammar mastery.

This is interpreted that the grammar mistakes they make when speaking are rarely responded by the foreign interlocutor. 
This shows that the teacher's role is still dominant in terms of correcting, this is supported in interview conversations that student with positive perceptions states that although they can produce many statements and questions, their grammar errors are still frequently found by their teachers, while students with negative perception states that they cannot apply the grammar learning that teachers have taught them to practice directly to foreign interlocutors, because they assume that before practicing speaking with the foreigners, learning grammar material must always be repeated in at least 3 meetings by practicing it with their classmates first so they can get used to it, because they feel nervous to talk to the foreign interlocutor as a stranger directly in 1 meeting.

This study also analyzed other factors in terms of facilities, it turns out the facility also affects the effectiveness of learning. $52 \%$ of students stated that they agreed on good facilities from the school to support the implementation of CCSC.

\section{CONCLUSION}

CCSC motivates students produce more utterances, this is evidenced from the students' responses which state that the teacher does not need to instruct them to ask and express questions and even though the grammar used is not very good and not critically responded by the foreign interlocutors, grammar correction from the teacher also helps remind them to always improve their grammar, but there are also those who state that grammar learning must always be repeated before students are given instructions to practice it.

Therefore, it is suggested that the teacher can implement CCSC in speaking class by preparing material that is done repeatedly or assigning students to practice with their friends first before practicing it with English speakers from different cultures to increase students' confidence in speaking.

The finding of the study cannot be generalized because this study is carried out in a limited period of classroom observation and interview, has limited participants, and the learning topic is only about Simple Present Tense.

Thus, for further researchers having the same interest in a similar topic, they are recommended to gain more detailed data by involving wider participants, a long period of classroom observation and deeper interview are also necessary to be taken. To add another insight, the use of the grammar observed can be extended, not only to Simple Present Tense, but also to the other tenses and wider aspects of grammar.

\section{REFERENCES}

College, B. (2015). Gen Z: Exploring middle and high schoolers' expectations for higher education. Basking Ridge: Barnes \& Noble College.

Coverdale-Jones, T. (2017). The use of video-conferencing as a communication tool for language learning: Issues and considerations. IALLT Journal of Language Learning Technologies, 32(1), 27-40. doi: 10.17161/iallt.v32i1.8308

Creswell, J.W. (2012). Educational research: planning conducting and evaluating quantitative and qualitative research $(4 t h$ ed.). Boston: Pearson education.

Eguchi, M. (2014). The effect of cross-cultural videoconferencing on EFL learners' English production. . Global Partners in Education Journal, 4(1), 5-15.

Fraenkel, J. R., Wallen, N. E., \& Hyun, H. H. (2012). How to design and evaluate research in education (8th ed.). New York: McGraw-Hill.

Guth, S., \& Marini-Maio, N. (2010). Close encounters of a new kind: The use of Skype and Wiki in telecollaboration. In Telecollaboration 2.0: Language, Literacies, and Intercultural Learning in the 21st Century, 413-426.

Huberman, A., \& Miles, M. (1994). Data Management and Analysis Method. In Handbook of Qualitative Research, N. Denizin \& Y. Lincon. Thousand Oaks: Sage

Ip, W. H. (2012). Video conferencing: Advantages and limitations in teaching intercultural communication in foreign language education. In The 5th edition of the international conference "ICT for Language Learning", 349-352.

Khan, U. I., Ayaz, M., \& Khan, S. (2016). Using Skype to develop English learners' speaking motivation. Sci.Int. , 28(5), 41-48.

Lin, C. (2007). EFL college students' perceptions of video-conferencingassisted English learning. English Teaching and Learning, 31, 77-116.

Loewen, S., \& Erlam, R. (2006). Corrective feedback in the chatroom: An experimental study. Computer Assisted Language Learning, 19(1), 1-14. doi: 10.1080/09588220600803311

Muhsin, M., \& Sastrawati, I. (2015). Ketergabungan pendidikan karakter dan positive feedback dalam pembelajaran Bahasa Inggris. Jurnal Keguruan dan Ilmu Pendidikan (JKIP) Unismuh Makassar, 2(3), 36-51

Nasr, E., \& Mustafa, E. (2018). The impact of YouTube, Skype and WhatsApp in improving EFL learners' speaking skill. International Journal of Contemporary Applied Researches, 5(5), 18-31.

Owada, K. (2005). The effective use of videoconferencing in cross-cultural English language instruction. The 9th Conference of Pan-Pacific Association of Applied Linguistics.

Piasecka, L., \& Tukiendorf, A. (2014). New Media and Perennial Problems in Foreign Language Learning and Teaching. Berlin: Springer.

Ritchie, J. (2013). Qualitative research practice: A guide for social science students and researchers. Sage Publication.

Shiozawa, Y. (2005). Strategic use of videoconferencing in intermediate EFL. Journal of the Faculty of International Studies, 16, 103-114.

Solikhah, I. (2016). Oral corrective feedback in speaking class of English Department. Lingua, 13(1), 87-102. doi: 10.30957/lingua.v13i1.14

Taillefer , L., \& Munoz-Luna, R. (2014). Developing oral skills through Skype: A language project analysis. Procedia - Social and Behavioral Sciences, 141(1), 260-264. doi: 10.1016/j.sbspro.2014.05.045

Tsukamoto, M., M, N., \& Senzaki, Y. (2009). Using Skype $\odot$ to connect a classroom to the world: Providing students an authentic language experience within the classroom. CamTESOL Conference on English Language Teaching, 5, 162-168. 